\title{
MOLECULAR ORBITAL STUDY OF THE FRAGMENTATION MECHANISM ON 5-HYDROXYTETRAZOLE
}

\author{
Kunio Wakia, Teruo kuriharab*, Shigeo Araib, and Yoshitada Koyamab \\ a Department of Applied Chemistry, Faculty of Engineering, \\ Toyo University, Kawagoe-shi, Saitama 350, Japan \\ b Department of Chemistry. Faculty of Science, Josai University, \\ Sakado-shi, Saitama 350-02, Japan
}

\begin{abstract}
The tautomerism of 5-hydroxytetrazole is discussed on the basis of its fragmentation patterns and molecular orbital calculations by MNDO and PM3 methods. The calculated results of the fully optimized structures of 5-hydroxytetrazole and radical cations indicate that, in the gaseous phase, the enol form is energetically preferred form.
\end{abstract}

\section{Introduction}

In a previous paper (1), the present first author examined the thermal decomposition of 5hydroxytetrazole 4 by use of sealed-cell, as a concerning research series about the availability of gas-generating chemicals. The main products were $\mathrm{N}_{2}$ and urazole, and included a small amount of a resinoid in the condensed phase. Small amounts of $\mathrm{CO}, \mathrm{CO}_{2}$, carbamoylazide, and trace amounts of $\mathrm{NH}_{3}$ and $\mathrm{H}_{2} \mathrm{O}$ were also found in the gaseous and sublimated products. According to the theory, tetrazole and 5-substituted tetrazoles are known to exist in either two or four tautomeric forms. The thermal decomposition, mass spectrometric fragmentation, and molecular orbital calculation of tetrazole and its derivatives have been examined in numerous studies (2-9). Razynska et al. (2) reported on the tautomerism of tetrazole 1, 5-methyltetrazole 2 , and associated isotopically substituted derivatives in the gaseous phase. It was demonstrated from the mass-spectrometric results, supported by semiempirical calculation (CNDO/2) and then only the $2 \mathrm{H}$ tautomer occurred in the gaseous phase. From the results of ab-initio calculation, Mazurek and Osman (3) reported that the preference of the $2 \mathrm{H}$ tautomer in gaseous phase, taken together with the suggested fragmentation from structure optimization, explained the observed fragmentation in the mass-spectra of 1 and 2 . According to the mass-spectrum analysis of 1,2 , and 5-aminotetrazole 3 , the most abundant ions are formed owing to the loss of $\mathrm{N}_{2}$ fragments (2-9). On the other hand, a characteristic feature of the high-resolution mass-spectrum of 5 hydroxytetrazole 4 showed at $\mathrm{m} / 286\left(\mathrm{M}^{+}\right), 69\left(\mathrm{M}^{+}-\mathrm{OH}\right), 44\left(\mathrm{CH}_{2} \mathrm{NO}\right)$, and $43\left(\mathrm{HN}_{3}\right.$ or $\left.\mathrm{CHNO}\right)$ (1). Compound 4 was found to have no fragment ion peak in its mass-spectrum owing to the loss of $\mathrm{N}_{2}$. Here, the investigations were extended to include the fragmentation of the tetrazole ring in 4 . along with the revision of several earlier reported results. To advance the further investigation of the properties of tetrazole tautomers, the full geometrical optimizations of the molecules were carried out by MNDO and PM3 methods. 


\section{Theoretical Procedure}

The molecular orbital calculations by MNDO and PM3 methods were performed with the application of MOPAC program (Version 6.01) (10). The geometries of the neutral species 1-4. and their radical cations $\mathbf{L}^{\prime}-\underline{L^{\prime}}$ were optimized with respect to all geometrical parameters using Broyden-Fletcher-Goldfrab-Shanno algorithm incorporated in the program. The transition states were determined either by the normal reaction coordinate method, or with the use of NLLSQ algorithm, refined by minimizing the energy gradient norm. Force constant calculations were conducted on the transitional state geometry to verify the existence of only one negative eigenvalue.

\section{Results and Discussion}

Tetrazole 1 can exist in two tautomeric forms, while 5-substituted tetrazoles 2-4 are known to exist in each four tautomeric form (2-9) (Fig. 1). First, the geometries of 1-4 were optimized. Table 1<smiles>c1nnn[nH]1</smiles>

1a<smiles>Nc1nnn[nH]1</smiles>

3a<smiles>c1nn[nH]n1</smiles>

16<smiles>Nc1nnn[nH]1</smiles>

3.<smiles>Cc1nnnn1I</smiles>

$\underline{29}$<smiles>N=c1[nH]nn[nH]1</smiles>

3c<smiles>Cc1nn[nH]n1</smiles>

$\underline{2 b}$<smiles></smiles>

3d<smiles>C=C1NNNC1=C</smiles>

$2 x$<smiles>Nn1nnnc1O</smiles>

4a<smiles>C=C1N=NNC1N</smiles>

2d

Figure 1: Illustrations of tautomeric forms of $1-4$

Table I: Heat of formation $\Delta \mathrm{H}_{\mathrm{f}}\left(\mathrm{kJmol}^{-1}\right)$ on tautomers 1-4 by MNDO and PM3 methods

\begin{tabular}{|c|c|c|c|c|c|}
\hline & \multicolumn{2}{|c|}{$\Delta \mathrm{H}_{\mathrm{f}}$} & & \multicolumn{2}{|c|}{$\Delta \mathrm{H}_{\mathrm{f}}$} \\
\hline & MNDO & PM3 & & MNDO & PM3 \\
\hline $1 \mathrm{a}$ & 225.279 & 360.870 & $3 a$ & 214.681 & 350.778 \\
\hline \multirow[t]{3}{*}{16} & 243.166 & 369.953 & $3 \mathrm{~b}$ & 232.170 & 358.393 \\
\hline & & & 3 ع & 277.567 & 392.041 \\
\hline & & & 30 & 319.469 & 432.797 \\
\hline $2 a$ & 177.213 & 316.992 & 4. & 16.468 & 173.945 \\
\hline $2 b$ & 194.477 & 328.674 & $4 \mathrm{~b}$ & 39.079 & 192.301 \\
\hline $2 c$ & 268.592 & 378.903 & $4 \varepsilon$ & 40.238 & 150.252 \\
\hline 20 & 313.649 & 429.747 & 4d & 91.701 & 198.937 \\
\hline
\end{tabular}


summarizes the values of the heat of formation $\left(\Delta \mathrm{H}_{\mathrm{f}}\right)$ of $1 \mathrm{a}-1 \mathrm{~b}, 2 \mathrm{a}-2 \mathrm{~d}, 3 \mathrm{a}-3 \mathrm{~d}$, and $4 \mathrm{a}-4 \mathrm{~d}$ obtained by MNDO and PM3 methods. The $1 \mathrm{H}$ tautomer $\mathrm{la}$ is preferred over $2 \mathrm{H}$ tautomer $\mathrm{Lb}$ by 17.89 and $9.08 \mathrm{kJmol}^{-1}$, according to MNDO and PM3 methods, respectively. On the other hand, the results of the $6-31 G^{* *}$, by Mazurek and Osman (3) reverse the evaluation of energy compared with the present MNDO and PM3 calculations. The difference in the optimized bond lengths does not exceed $0.03 \AA$ for tautomers 1-4. The largest change in the optimized angles was about $3.0^{\circ}$ for tautomers of 1-4. The microwave estimate of the dipole moment of $1 \mathrm{~b}$ was $2.19 \mathrm{D}$ (11) and the present MNDO and PM3 calculations were 1.89D and 2.34D, respectively. Krugh and Gold (11) obtained a dipole moment 5.30D for the $1 \mathrm{H}$ tautomer 1a. The present MNDO and PM3 calculations gave dipole moments for $1 \mathrm{a}$ of $5.09 \mathrm{D}$ and 5.41D, respectively. Two dipole moments were also supported by Krugh and Gold (11). The positions of the lone-pair electron on the nitrogen atom in $\mathbf{1 a}$ and $\mathbf{1 b}$ are located at $\mathrm{N}(2)$ and $\mathrm{N}(4)$ atom, respectively. If it is assumed that the lone-pair electron on $\mathrm{N}(2)$ or $\mathrm{N}(4)$ atom is ionized by electronic impact, then $\mathrm{N}_{2}$ fragment is expected. For $\mathbf{2 a}$ and $\mathbf{2 d}$ tautomers, the position of the lone-pair electron is located at $\mathrm{N}(4)$ atom. For $4 \mathrm{a}$ and $4 \mathrm{~b}$ tautomers, the positions of the lone-pair electron are located at $\mathrm{N}(3)$ and $\mathrm{N}(4)$ atom, respectively. Under such circumstances, the preferred fragmentation of tautomers 2-4 could yield $\mathrm{N}_{2}$ fragments. Therefore, the results expected for tautomer 4 did not agree with the observed mass-spectra of 4 . Second, the geometries of the radical cations 1'-4' were optimized.

Table II : Heat of formation $\Delta \mathrm{H}_{\mathrm{f}}\left(\mathrm{kJmol}^{-1}\right)$ on the radical cations 1'- 4' by MNDO and PM3 methods

\begin{tabular}{|c|c|c|c|c|c|}
\hline \multicolumn{3}{|c|}{$\Delta \mathrm{H}_{\mathrm{f}}$} & & \multicolumn{2}{|c|}{$\Delta \mathrm{H}_{\mathrm{f}}$} \\
\hline & MNDO & PM3 & & MNDO & PM3 \\
\hline $1 \mathbf{a}^{\prime}$ & 1227.167 & 1376.440 & $3 \mathrm{a}^{\prime}$ & 1116.069 & 1211.795 \\
\hline \multirow[t]{3}{*}{$1 \mathrm{~b}^{\prime}$} & 1254.313 & 1343.336 & $3 b^{\prime}$ & 1100.584 & 1174.679 \\
\hline & & & $3 c^{\prime}$ & 1152.960 & 1226.422 \\
\hline & & & $3 d^{\prime}$ & 1226.414 & 1297.103 \\
\hline $2 \mathrm{a}^{\prime}$ & 1173.093 & 1300.546 & $4 \mathrm{a}^{\prime}$ & 994.784 & 1137.843 \\
\hline $2 b^{\prime}$ & 1177.457 & 1265.405 & $4 b^{\prime}$ & 983.011 & 1115.392 \\
\hline $2 c^{\prime}$ & 1045.255 & 1158.211 & $4 c^{\prime}$ & 992.449 & 1072.920 \\
\hline $2 d^{\prime}$ & 1116.806 & 1226.473 & $4 d^{\prime}$ & 1042.071 & 1107.287 \\
\hline
\end{tabular}

Table II summarizes the values of $\Delta \mathrm{H}_{\mathrm{f}}$ for the radical cations $(1 \mathrm{a} !-1 \mathrm{~b} ! .2 \mathrm{a} !-2 \mathrm{~d} ! .3 \mathrm{a} !-3 \mathrm{~d} !$. and $4 \mathrm{a}$ !4d.) obtained by MNDO and PM3 methods. The relevant geometrical parameters for PM3 method of the tautomers are summarized in Table III. From the date listed in Table II, 1H tautomer 1a' is preferred over $2 \mathrm{H}$ tautomer $1 \mathbf{b}^{\prime}$ by $27.15 \mathrm{kJmol}^{-1}$ according to MNDO method, but $1 \mathbf{b}^{\prime}$ is preferred over 1a' by $33.10 \mathrm{kJmol}^{-1}$ using PM3 method. Mazurek and Osman (3) reported that on the radical 1b:. the $N(3)-N(2)$ bond length increased beyond $2 \AA$ during optimization at the UHF/3-21G level. In the UHF/PM3 optimized structures, the $N(3)-N(2)$ bond lengths of $1 \mathbf{b}^{\prime}, 2 \mathbf{b}^{\prime}$, and $4 \mathbf{b}^{\prime}$ were calculated as $1.783 \AA, 1.749 \AA$, and $1.673 \AA$, respectively, in agreement with the results of Mazurek 
and Osman. Thus, the transition states and energies of activation (Ea) for the radical cations $\mathbf{L}^{\prime}-\mathbf{4}^{\prime}$ were determined by UHF/PM3 method. The $\Delta \mathrm{H}_{\mathrm{f}}$ values of $4 \mathrm{a}^{\prime}-4 \mathrm{~d}^{\prime}$ were calculated by PM3 method as $1137.8,1115.4,1072.9$, and $1107.3 \mathrm{kJmol}^{-1}$, respectively. Compound $4 \mathrm{c}^{\prime}$ had the most stable

Table III : Optimized geometries of radical cations 1'-4' on calculation by PM3 method

\begin{tabular}{|c|c|c|c|c|c|c|c|c|}
\hline \multirow{2}{*}{\multicolumn{2}{|c|}{$\begin{array}{l}\text { Structural } \\
\text { parameters }\end{array}$}} & \multicolumn{2}{|c|}{ Tetrazole (1) } & & \multicolumn{4}{|c|}{ 5-Methyltetrazole (2) } \\
\hline & & $1 \mathrm{a}^{\prime}$ & $1 \mathrm{~b}^{\prime}$ & & $2 a^{\prime}$ & $2 \mathbf{b}^{\prime}$ & $2 c^{\prime}$ & $2 d^{\prime}$ \\
\hline & \multicolumn{4}{|c|}{ Bond lengths $(\AA)$} & \multicolumn{4}{|c|}{ Bond lengths $(\AA)$} \\
\hline N1N2 & & 1.648 & 1.252 & & 1.302 & 1.251 & 1.352 & 1.379 \\
\hline N2N3 & & 1.200 & 1.783 & & 1.408 & 1.749 & 1.268 & 1.386 \\
\hline $\begin{array}{l}\text { N3N4 } \\
\text { N4C5 }\end{array}$ & & $\begin{array}{l}1.403 \\
1.404\end{array}$ & $\begin{array}{l}1.175 \\
1.463\end{array}$ & & $\begin{array}{l}1.238 \\
1.452\end{array}$ & $\begin{array}{l}1.180 \\
1.473\end{array}$ & $\begin{array}{l}1.351 \\
1.402\end{array}$ & $\begin{array}{l}1.246 \\
1.434\end{array}$ \\
\hline \multirow[t]{2}{*}{$\mathrm{C} 5 \mathrm{~N} 1$} & & 1.329 & 1.401 & & 1.413 & 1.409 & 1.402 & 1.413 \\
\hline & \multicolumn{4}{|c|}{ Bond angles (degrees) } & \multicolumn{4}{|c|}{ Bond angles (degrees) } \\
\hline N1N2N3 & & 104.42 & 104.31 & & 108.34 & 105.14 & 109.43 & 108.06 \\
\hline N2N3N4 & & 113.65 & 99.69 & & 109.50 & 100.89 & 109.64 & 109.91 \\
\hline N3N4C5 & & 109.87 & 117.64 & & 110.46 & 116.43 & 109.67 & 111.29 \\
\hline N4C5N1 & & 106.68 & 106.22 & & 102.35 & 105.86 & 101.51 & 103.97 \\
\hline C5N1N2 & & 105.18 & 112.14 & & 109.36 & 111.67 & 109.75 & 106.60 \\
\hline \multirow{2}{*}{$\begin{array}{l}\text { Structural } \\
\text { parameters }\end{array}$} & \multicolumn{4}{|c|}{ 5-Aminotetrazole (3) } & \multicolumn{4}{|c|}{ 5-Hydroxytetrazole (4) } \\
\hline & $3 \mathrm{a}^{\prime}$ & $3 b^{\prime}$ & $3 c^{\prime}$ & $3 d^{\prime}$ & $4 a^{\prime}$ & $4 b^{\prime}$ & $4 c^{\prime}$ & $4 d^{\prime}$ \\
\hline & \multicolumn{4}{|c|}{ Bond lengths $(\AA)$} & \multicolumn{4}{|c|}{ Bond lengths $(\AA)$} \\
\hline $\begin{array}{l}\text { N1N2 } \\
\text { N2N3 }\end{array}$ & $\begin{array}{l}1.316 \\
1.331\end{array}$ & $\begin{array}{l}1.302 \\
1.395\end{array}$ & $\begin{array}{l}1.337 \\
1.280\end{array}$ & $\begin{array}{l}1.344 \\
1.453\end{array}$ & $\begin{array}{l}1.315 \\
1.390\end{array}$ & $\begin{array}{l}1.270 \\
1.673\end{array}$ & $\begin{array}{l}1.308 \\
1.310\end{array}$ & $\begin{array}{l}1.317 \\
1.668\end{array}$ \\
\hline $\begin{array}{l}\text { N3N4 } \\
\text { N4C5 }\end{array}$ & $\begin{array}{l}1.270 \\
1.426\end{array}$ & $\begin{array}{l}1.251 \\
1.436\end{array}$ & $\begin{array}{l}1.335 \\
1.420\end{array}$ & $\begin{array}{l}1.223 \\
1.467\end{array}$ & $\begin{array}{l}1.240 \\
1.466\end{array}$ & $\begin{array}{l}1.194 \\
1.478\end{array}$ & $\begin{array}{l}1.307 \\
1.478\end{array}$ & $\begin{array}{l}1.182 \\
1.518\end{array}$ \\
\hline \multirow[t]{2}{*}{$\mathrm{C} 5 \mathrm{~N} 1$} & 1.416 & 1.394 & 1.422 & 1.473 & 1.410 & 1.402 & 1.478 & 1.514 \\
\hline & \multicolumn{4}{|c|}{ Bond angles (degrees) } & \multicolumn{4}{|c|}{ Bond angles (degrees) } \\
\hline N1N2N3 & 109.44 & 110.66 & 109.86 & 108.73 & 109.26 & 106.68 & 110.91 & 106.96 \\
\hline N2N3N4 & 110.73 & 108.72 & 110.17 & 109.41 & 110.69 & 104.14 & 111.11 & 105.51 \\
\hline N3N4C5 & 109.15 & 108.62 & 109.40 & 112.33 & 108.60 & 112.22 & 109.48 & 115.83 \\
\hline N4C5N 1 & 102.67 & 105.76 & 101.12 & 102.63 & 103.80 & 107.97 & 98.94 & 102.95 \\
\hline C5N1N2 & 108.02 & 106.25 & 109.44 & 106.83 & 107.66 & 109.00 & 109.56 & 108.62 \\
\hline
\end{tabular}

cation among these tautomers. The total bicentre energies and properties of the transitional states of the radical cations $4 a^{-4 a}$ are listed in Table IV. An analysis of the values of the

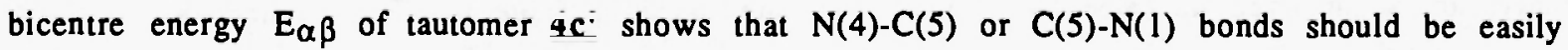
broken. To determine exactly what happens during and after the $\mathrm{N}(4)-\mathrm{C}(5)$ bond or $\mathrm{C}(5)-\mathrm{N}(1)$ bond fission, the reaction coordinate calculations were performed by stretching the $N(4)-C(5)$ or $\mathrm{C}(5)-\mathrm{N}(1)$ bonds in the radical cation $\mathbf{4 c}^{\prime}$. The reaction pathway was calculated by the appropriate reaction coordinate $\mathrm{N}(4)-\mathrm{C}(5)$ bond lengths. The geometry of the molecule when the bond is stretched to $2.247 \AA$ is suggestive of a transitional state, since there is only one negative 
eigenvalue of $295.6 \mathrm{~cm}^{-1}$. From the results of normal coordination analysis, the most probable fragmentation of $4 \mathrm{c}^{\prime}$ would yield $\mathrm{N}_{3} \mathrm{H}$ or $\mathrm{NCOH}$ fragments (Figure $2 \mathrm{~A}$ ). The activation energy for this process was determined as $86.73 \mathrm{~kJ} \mathrm{~mol}^{-1}$. The optimization of the transitional state of radical cation $4 \mathrm{c}^{\text {: }}$ was accomplished by stretching the $\mathrm{C}(5)-\mathrm{N}(1)$ bond as the reaction coordinate

Table IV : Calculated properties of the transitional states for the bond cleavage of $4 \mathrm{a}:-4 \mathrm{~d}$ :

\begin{tabular}{|c|c|c|c|c|c|c|}
\hline & & \multirow[b]{2}{*}{$E \alpha \beta^{b)}$} & \multicolumn{4}{|c|}{$T S^{2)}$} \\
\hline & & & coordinate & $\Delta H_{f}{ }^{c)}$ & $v^{d)}$ & $\mathrm{Ea}^{e)}$ \\
\hline \multirow[t]{5}{*}{$4 \mathbf{a}_{-}^{\prime}$} & N1N2 & -16.506 & & & & \\
\hline & N2N3 & -13.032 & & not deter & & \\
\hline & N3N4 & -20.260 & & & & \\
\hline & N4C5 & -13.311 & 2.145 & 1266.75 & 503 & 170.71 \\
\hline & $\mathrm{C} 5 \mathrm{~N} 1$ & -15.907 & & & & \\
\hline \multirow[t]{5}{*}{$4 b^{\prime}$} & N1N2 & -18.803 & & & & \\
\hline & N2N3 & -7.178 & 2.104 & 1135.45 & 477 & 19.08 \\
\hline & N3N4 & -23.335 & & & & \\
\hline & N4C5 & -12.602 & & & & \\
\hline & C5N1 & -16.011 & & & & \\
\hline \multirow[t]{5}{*}{$4 c !$} & N1N2 & -16.764 & & & & \\
\hline & N2N3 & -16.345 & & & & \\
\hline & N3N4 & -16.780 & & & & \\
\hline & N4C5 & -13.111 & 2.247 & 1157.34 & 296 & 86.73 \\
\hline & $\mathrm{C} 5 \mathrm{~N} 1$ & -13.115 & 2.247 & 1165.70 & 297 & 86.65 \\
\hline \multirow[t]{5}{*}{ 4d' } & N1N2 & -16.992 & & & & \\
\hline & N2N3 & -7.140 & 1.995 & 1114.87 & 292 & 7.28 \\
\hline & N3N4 & -24.047 & & & & \\
\hline & N4C5 & -11.916 & & & & \\
\hline & C5N1 & -11.126 & & & & \\
\hline
\end{tabular}
a) Transition state.
b) Bicentre energy in eV.
c) Heat of formation in $\mathrm{kJmol}^{-1}$.
d) Imaginary mode in $\mathrm{cm}^{-1}$. e) Energy of activation in $\mathrm{kJmol}^{-1}$.

with the application of NLLSQ algorithm. When the $\mathrm{C}(5)-\mathrm{N}(1)$ bond is stretched to $2.247 \AA$, the geometry of the molecule suggests a transitional state, since there is only one negative eigen value of $296.8 \mathrm{~cm}^{-1}$. In Figure 2B, the most probable fragmentation process of $4 \mathrm{c}^{\prime}$ would yield $\mathrm{N}_{2} \mathrm{H}$ or $\mathrm{CON}_{2} \mathrm{H}$ fragments. The activation energy calculated for this process was $86.65 \mathrm{kJmol}^{-1}$

(Table IV). The analysis of the $E_{\alpha \beta}$ values of 4 d' shows that $N(2)-N(3)$ bond should be readily broken in this radical. The transitional state was calculated by $N(2)-N(3)$ bond length as the reaction coordinate. In Figure $2 \mathrm{C}$, the preferred fragmentation of $4 \mathrm{~d}^{\prime}$ could yield $\mathrm{N}_{2}$ or $\mathrm{CON}_{2} \mathrm{H}_{2}$ fragments. The activation energy for the process was $7.28 \mathrm{kJmol}^{-1}$ (Table IV). For the radical cation $4 \mathrm{~b}^{\prime}$, from the results of the imaginary mode (Figure 2D) with a eigenvalue of $477 \mathrm{~cm}^{-1}$, the most probable fragmentation of $4 b^{\prime}$ could yield $\mathrm{N}_{3} \mathrm{H}$ or $\mathrm{NCOH}$ fragments. 


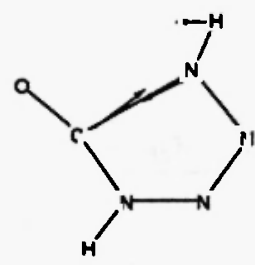

A

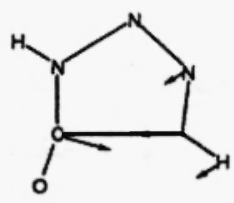

B

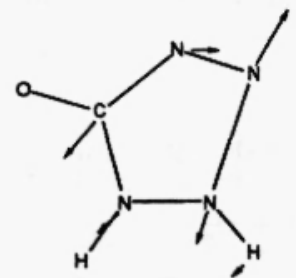

C

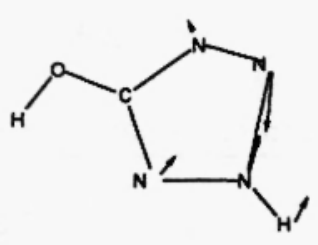

D

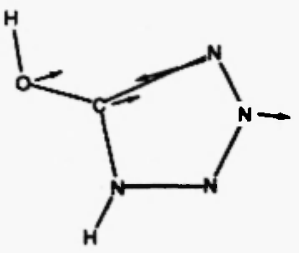

E

Figure 2: Illustrations of vectors of imaginary modes

The $E_{\alpha \beta}$ values for the radical cation $4 a^{\prime}$ showed that $N(2)-N(3)$ or $N(4)-C(5)$ bonds should be more readily broken. When the reaction pathway was calculated by $N(2)-N(3)$ bond length as the reaction coordinate, the transitional state could not be determined. Because two negative eigenvalues were found. When the $\mathrm{N}(4)-\mathrm{C}(5)$ bond of $4 \mathrm{a}^{\prime}$ is stretched to $2.145 \AA$, the results are suggestive of a transitional state with one negative eigenvalue of $503.0 \mathrm{~cm}^{-1}$. In Figure $2 \mathrm{E}$, the preferred fragmentation of $4 \mathrm{a}^{\prime}$ could yield $\mathrm{N}_{3} \mathrm{H}$ or, $\mathrm{NCOH}$ fragments. While the radical $4 \mathrm{c}^{\prime}$ had the smallest $\Delta H_{f}$ value, the value of Ea determined for $4 c^{\prime}$ was larger than those of $4 b^{\prime}$ and $4 d^{\prime}$. Therefore, the fragmentation mechanism from $4 \mathrm{a}^{\prime}$ could not explain the observed fragmentation in the mass-spectra of 4 . The results of the present UHF/PM3 level calculations suggest that the preferred fragmentation of $4^{\prime}$ could yield fragments of $\mathrm{N}_{2}$ or $\mathrm{COHN}_{2} \mathrm{H}_{2}$ from $4 d^{\prime}$ when comparing with the Ea values. The difference between the Ea values in the transitional states of $4 b^{\prime}$ and $4 \mathrm{~d}$.' was small. By PM3 method, it is found that $4 \mathrm{~d}^{\prime}$ was slightly preferred over $4 \mathrm{~b}^{\prime}$ by $8.11 \mathrm{kJmol}^{-1}$ (Table II). By MNDO method, however, $4 \mathrm{~b}^{\prime}$ was preferred over $4 \mathrm{~d}^{\prime}$ by $59.06 \mathrm{kJmol}^{-1}$. From the above results, the most preferred fragmentation of the radical cation $4^{\prime}$ could yield $\mathrm{N}_{3} \mathrm{H}$ or $\mathrm{CHNO}$ fragments, because the most susceptible bond for stretching is the $N(2)-N(3)$ in radical $4 b^{\prime}$. The total bicentre energies of $\mathbf{L}^{\prime}, \mathbf{2}$, and $\mathbf{Z}^{\prime}$ are listed $n$ Table $\mathrm{V}$. The transitional states and energies

Table V: Total bicentre energy $\mathrm{E} \alpha \beta(\mathrm{eV})$ of the radical cations 1 '-3' by UHF/PM3 method

\begin{tabular}{|c|c|c|c|c|c|c|c|c|c|c|}
\hline \multirow[b]{2}{*}{ EOß } & \multicolumn{2}{|c|}{ Tetrazole } & \multicolumn{4}{|c|}{ 5-Methyltetrazole } & \multicolumn{4}{|c|}{ 5-Aminotetrazole } \\
\hline & $1 . a^{\prime}$ & 1.b.' & 2.a. & 2.b! & $\underline{2} c^{\prime}$ & 2.d.' & $\underline{3} \mathbf{a}^{\prime}$ & $\underline{\mathbf{3} \mathbf{b}^{\prime}}$ & 3c: & 3.d.' \\
\hline N1N2 & -7.63 & -19.58 & 16.97 & -19.71 & -14.79 & -14.50 & -16.47 & -17.50 & -15.43 & -15.86 \\
\hline N2N3 & 2.54 & -4.88 & 12.41 & -5.53 & -18.61 & -13.22 & -15.24 & -13.24 & -17.90 & -11.27 \\
\hline N3N4 & -12.12 & -24.55 & -20.39 & -24.26 & -14.81 & -19.88 & -18.42 & -19.82 & -15.52 & -21.31 \\
\hline $\mathrm{N} 4 \mathrm{C} 5$ & -15.80 & -12.89 & -13.99 & -12.78 & -17.17 & -14.86 & -15.26 & -14.88 & -16.58 & -13.70 \\
\hline C5N 1 & -20.04 & -15.85 & .16 .08 & -15.66 & -17.18 & -16.29 & -17.19 & -16.43 & -16.20 & -13.53 \\
\hline
\end{tabular}

of activation of $1 \mathrm{a}^{\prime}$ and $1 \mathrm{~b}^{\prime}$ were carried out in a manner that stated above. The values of the $\mathrm{E}_{\alpha \beta}$ for $1 \mathrm{a}^{\prime}$ and $1 \mathrm{~b}^{\prime}$ revealed that the respective bonds $\mathrm{N}(1)-\mathrm{N}(2)$ and $\mathrm{N}(2)$ )-N(3) should be most readily broken. The transition state of the radical $1 \mathrm{a}^{\prime}$ was calculated by $N(1)-N(2)$ bond as the reaction coordinate. The geometry of the molecule when the bond is stretched to $2.053 \AA$ suggests 
a transitional state. From the results of the imaginary mode (Figure 3A), the most probable fragmentation of $1 \mathrm{a}^{\prime}$ would yield a $\mathrm{N}_{2} \mathrm{H}$ fragment. The activation energy for this process was calculated $26.53 \mathrm{kJmol}^{-1}$. The geometry of the molecule in $1 \mathbf{b}^{\prime}$ when the bond is stretched $2.096 \AA$

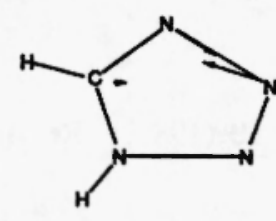

A

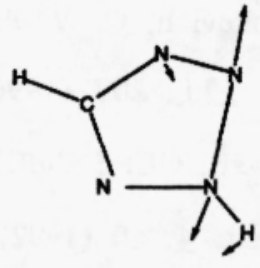

$\mathbf{B}$

Figure 3 : Pllustrations of vectors of imaginary modes

suggests a transitional state with one negative eigenvalue of $459.60 \mathrm{~cm}^{-i}$. The most probable fragmentation of $1 \mathbf{b}^{\prime}$ might yield a $\mathrm{N}_{2}$ fragment (Figure 3B). The activation energy for this process is $10.67 \mathrm{kJmol}^{-1}$. Consequently, for the radical cation 1 ., comparing with the Ea values, the most abundant ions are formed due to the loss of $\mathrm{N}_{2}$ fragments. The present UHF/PM3 level calculations reasonably could explain the preferential bond breaking observed in the mass spectrum of tetrazole 1 . For the radical cation 2b'. when $N(2)-N(3)$ bond was stretched to $1.839 \AA$, only one negative eigenvalue of $469.8 \mathrm{~cm}^{-1}$ was found. From a vector analysis of $469.8 \mathrm{~cm}^{-1}$, the most probable fragmentation of $2 \mathrm{~b}^{\prime}$ might yield $\mathrm{N}_{2}$ or, $\mathrm{CH}_{3} \mathrm{CN}_{2} \mathrm{H}$ fragments.

\section{Acknowledgments}

The authors are grateful to Dr. Noboru Motohashi, Meiji College of Pharmacy, Japan, for reviewing the draft and making helpful comments.

\section{References}

1. K. Waki and T. Yamashita, Kogyo Kayaku. (in Japanese). 53, 238 (1992)

2. A. Razynska, A. Tempczyk, E. Malinski, J. Szafranek, Z. Grzonka and P. Hermann,

J. Chem. Soc. Perkin Trans II, 379 (1983)

3. A. P. Mazurek and R. Osman, J. Phys. Chem. 89, 460 (1985)

4. I. Jano, J. Phys. Chem. 25, 7694 (1991)

5. A. I. Lesnikovich, S. V. Levchik, A. I. Balabanovich, O. A. Ivashkevich and P. N. Gaponik, Thermochimi. Acta. 200. 427 (1992)

6. S. V. Levchik, O. A. Ivashkevich, A. I. Balabanovich, A. I. Lesnikovich, P. N.

Gaponik and L. Costa, Thermochimi. Acta. 207. 115 (1992) 
7. A. I. Lesnikovich, O. A. Ivashkevich, V. A. Lyutsko, G. V. Printsev, K. K. Kovalenko, P. N. Gaponik and S. V. Levchik, Thermochimi. Acta. 145. 195 (1989)

8. S. V. Vyazovkin, A. I. Lesnikovich and V. A. Lyutsko, Thermochimi. Acta. 165 . 17 (1990)

9. A. I. Lesnikovich, O. A. Ivashkevich, G. V. Printsev, P. N. Gaponik and S. V. Levchik, Thermochimi. Acta. 171. 207 (1990)

10. MOPAC ver. 6.00, J. J. P. Stewart, QCPE Bull. 2, 10 (1989) Revised as ver 6.03 by Yoshihisa Inoue, JCPE Newslett. 4, 60 (1992)

11. W. D. Krugh and L. P. Gold, J. Mol. Spectrosc. 49, 423 (1974)

Received April 9, 1995 